\title{
Author Correction: Coherent spin dynamics of electrons and holes in $\mathrm{CsPbBr} 3$ perovskite crystals
}

\author{
Vasilii V. Belykh (1) 1, Dmitri R. Yakovlev (1) 1,2, Mikhail M. Glazov (1) 2, Philipp S. Grigoryev (1) 3, Mujtaba Hussain ${ }^{4}$, \\ Janina Rautert (1) 1, Dmitry N. Dirin (10 5, Maksym V. Kovalenko (1) ${ }^{5,6}$ \& Manfred Bayer (1) 1,2
}

Correction to: Nature Communications https://doi.org/10.1038/s41467-019-08625-z, published online 08 February 2019

The original version of this Article contained an error in Fig. 2c, in which the numbers on the $y$-axis were given in the wrong order: ' 800 ' at the bottom through to ' 0 ' at the top. This has been corrected in both the PDF and HTML versions of the Article.

Also, the Source Data file initially published online was corrupted and was replaced.

Published online: 15 April 2019

\begin{abstract}
(c) (i)
Open Access This article is licensed under a Creative Commons Attribution 4.0 International License, which permits use, sharing, adaptation, distribution and reproduction in any medium or format, as long as you give appropriate credit to the original author(s) and the source, provide a link to the Creative Commons license, and indicate if changes were made. The images or other third party material in this article are included in the article's Creative Commons license, unless indicated otherwise in a credit line to the material. If material is not included in the article's Creative Commons license and your intended use is not permitted by statutory regulation or exceeds the permitted use, you will need to obtain permission directly from the copyright holder. To view a copy of this license, visit http://creativecommons.org/licenses/by/4.0/.
\end{abstract}

(C) The Author(s) 2019

\footnotetext{
${ }^{1}$ Experimentelle Physik 2, Technische Universität Dortmund, D-44221 Dortmund, Germany. ${ }^{2}$ loffe Institute, Russian Academy of Sciences, 194021 St. Petersburg, Russia. ${ }^{3}$ Spin Optics Laboratory, St. Petersburg State University, 199034 St. Petersburg, Russia. ${ }^{4}$ Centre for Micro and Nano Devices, Department of Physics, COMSATS University, 44000 Islamabad, Pakistan. ${ }^{5}$ Laboratory of Inorganic Chemistry, Department of Chemistry and Applied Biosciences, ETH Zürich, CH-8093 Zürich, Switzerland. ${ }^{6}$ Laboratory for Thin Films and Photovoltaics, Empa-Swiss Federal Laboratories for Materials Science and Technology, CH-8600 Dübendorf, Switzerland. Correspondence and requests for materials should be addressed to V.V.B. (email: vasilii. belykh@tu-dortmund.de) or to D.R.Y. (email: dmitri.yakovlev@tu-dortmund.de)
} 